\title{
A Novel Polymeric Conservation Method of Historical Outdoor Ceramics
}

\author{
Tomas PETRE்NAS ${ }^{1}$, Olga OPUCHOVIČ ${ }^{1}$, Jūratẻ SENVAITIENE் ${ }^{2}$, \\ Aldona BEGANSKIENE ${ }^{1}$, Aivaras KAREIVA ${ }^{1}$ *
}

\author{
${ }^{1}$ Department of Inorganic Chemistry, Vilnius University, Naugarduko 24, LT-03225 Vilnius, Lithuania \\ ${ }^{2}$ Department of Applied Chemistry, Vilnius University, Naugarduko 24, LT-03225 Vilnius, Lithuania
}

crossref http://dx.doi.org/10.5755/j01.mm.21.2.6823

Received 31 March 2014; accepted 17 May 2014

\begin{abstract}
In this study, a novel conservation method was developed for the protection of historical outdoor ceramics. The historical ceramics from monastery of "San Filippo di Fragalà" (Sicily, Italy) were chosen for this study. Polymeric films on the surface of ceramics specimens were formed using Silres BS 16 as a precursor. For the comparison, the material Paraloid B-82, which is already known in the conservation practice, was also used for the formation of protective coatings on historical ceramics. The investigated samples were characterized by SEM, TG, EDX, XRD methods and contact angle measurements. The results obtained showed that ceramic samples were successfully preserved and saturated by Silres BS 16 with forming effective polymeric coatings on ancient ceramics surfaces.

Keywords: Ancient ceramics, conservation, Silres BS 16, SEM, TG, contact angle.
\end{abstract}

\section{INTRODUCTION}

Scientists from the field "Preservation of cultural work" are currently dealing with the problem of conservation of glass, ceramics, paper, amber, wood, metals and alloys, without disturbing the structure of the raw material [1-8]. However the preparation of low cost and environmentally benign technological procedures for the conservation of ancient pottery and ceramics still is a big problem. Moreover, the conservation process can be greatly influenced by specific chemical reactions appearing due to the different chemical compositions in the object of conservation and protective coatings.

Standard methods for the restoration of historical ceramics are used in the practice. However, individual methods in many cases should be created to preserve the originality of historical object [9]. The polymeric conservation method of ceramics is one of the oldest and used in the practice of restoration already from $1960[10,11]$. Variety of polymeric materials has been investigated for the treatment of ceramic surfaces [12-14]. Recently the sol-gel processing route was also suggested for the preservation of ceramic objects $[15,16]$. However, the conservation process can be greatly influenced by specific chemical reactions appearing due to the different chemical compositions in the object of conservation and protective coatings. Therefore, to avoid the possible interactions careful characterization of ceramic sample should be done prior and after consolidation [17-19]. Thus, in all cases the conservation treatment should be selected with care preventing the degradation of surface of ceramic during the conservation processing [20-22].

The aim of this study was to develop a novel of low cost and environmentally benign conservation method for

\footnotetext{
${ }^{*}$ Corresponding author. Tel. +370-5-2193110; fax.: +370-5-2330987. E-mail address: aivaras.kareiva@chf.vu.lt (A. Kareiva)
}

outdoor historical ceramic. The historical ceramics from monastery of "San Filippo di Fragalà" (Sicily, Italy) were chosen for study [23, 24]. For comparison, the most common protective product, Paraloid B-82, used in the protection of historical ceramics, was also applied.

\section{EXPERIMENTAL}

The historical ancient ceramics from monastery of "San Filippo di Fragalà" (Sicily, Italy) have been chosen for this study. For all experiments analytical grade reagents were used: acetone (VWR International GmbH, Austria), ethanol (AB "Stumbras", Lithuania), Silres BS 16 (55\% aqueous solution of potassium methylsiliconate, Wacker, Germany) and Paraloid B-82 (5\% solution of copolymer of $50 \%$ ethylacrylate (EA) and $50 \%$ methylmetacrylate (MMA) in mixture of ethanol and acetone $(3: 1)$, Rohm and Haas Deutschland GmbH, Germany).

To obtain protective coatings, the $250 \mathrm{mg}$ of ceramic specimens were milled in an agate mortar, pressed to the pellets, dip-coated for 2 min in the solutions of polymers and dried in a desiccator.

The ceramic samples were characterized by powder X-ray diffraction analysis (XRD) performed with a MiniFlex II Rigaku powder diffractometer working in Bragg-Brentano $(\theta / 2 \theta)$ geometry and using $\mathrm{CuK} \alpha_{1}$ radiation. The data were collected at a step of $0.01^{\circ}$ and at speed of $0.06 \mathrm{~s} / \mathrm{step}$. The morphology and microstructure of ceramic samples were examined by scanning electron microscopy (SEM) on EVO $50 \mathrm{EP}$ scanning electron microscope operated in secondary electron mode (SE) and connected with EDX analyser Helios NanoLab 650. Thermogravimetric analysis (TG) was performed using STA6000 Pyris 1 Perkin-Elmer thermobalance system. The contact angle measurements were performed using KSV Instruments LTD (MODEL CAM 200) equipment. 


\section{RESULTS AND DISCUSSION}

The phase composition of ceramic sample was determined by XRD analysis. As was expected, the X-ray diffraction pattern exhibited multiphase character showing that the investigated ancient ceramic specimen from archaeological monastery is polycrystalline sample (Figure 1).

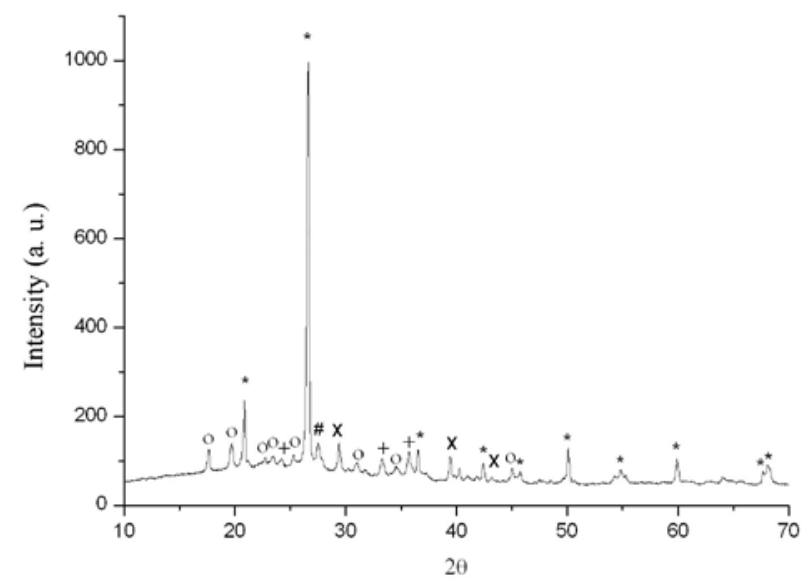

Fig. 1. XRD pattern of archaeological ceramic sample from monastery of "San Filippo di Fragalà" (Sicily, Italy). The crystalline phases are marked: * - quartz, $\mathrm{SiO}_{2}(\mathrm{PDF}$ [461045]), + - hematite, $\mathrm{Fe}_{2} \mathrm{O}_{3}$ (PDF [89-599]), $\mathrm{x}$ - calcite, $\mathrm{CaCO}_{3}$ (PDF [5-586]), o - potassium aluminium trisilicate, $\mathrm{KAl}_{3} \mathrm{Si}_{3} \mathrm{O}_{11}$ (PDF [46-741]), \# - microcline, $\mathrm{KAlSi}_{3} \mathrm{O}_{8}$ (PDF [19-926])

As seen, the sample is characterized by the presence of quartz $\left(\mathrm{SiO}_{2}\right)$ as a main phase. The second main crystalline component of this ceramic sample evidently is calcite $\left(\mathrm{CaCO}_{3}\right)$. The secondary phases, such as potassium aluminium trisilicate $\left(\mathrm{KAl}_{3} \mathrm{Si}_{3} \mathrm{O}_{11}\right)$ and microcline $\left(\mathrm{KAlSi}_{3} \mathrm{O}_{8}\right)$ were also identified. Besides, the negligible amount of hematite $\left(\mathrm{Fe}_{2} \mathrm{O}_{3}\right)$ phase was also determined.

Scanning electron microscopy (SEM) was employed for the investigation of specific surface morphological features of ancient outdoor ceramics. The micrograph obtained in secondary electron mode for the archaeological sample is shown in Figure 2, prior to the treatment.

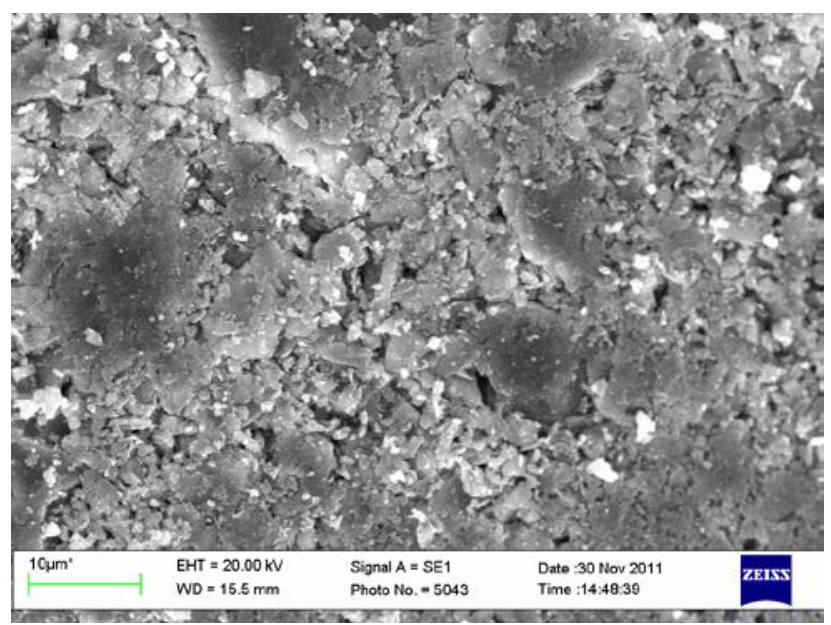

Fig. 2. SEM micrograph of archaeological ceramic sample from monastery of "San Filippo di Fragalà" (Sicily, Italy)
As seen, the surface of sample contains plate-like grains with different crystallite size ranging from $1 \mu \mathrm{m}$ to $5 \mu \mathrm{m}$. Besides, the micrograph reveals a broad distribution of agglomerates of fine particles with porous structure. The voids and cracks with various arbitrary shapes are also seen.

The SEM micrographs of the ceramic samples after coating with Paraloid B-82 and Silres BS 16 are shown in Figure 3.
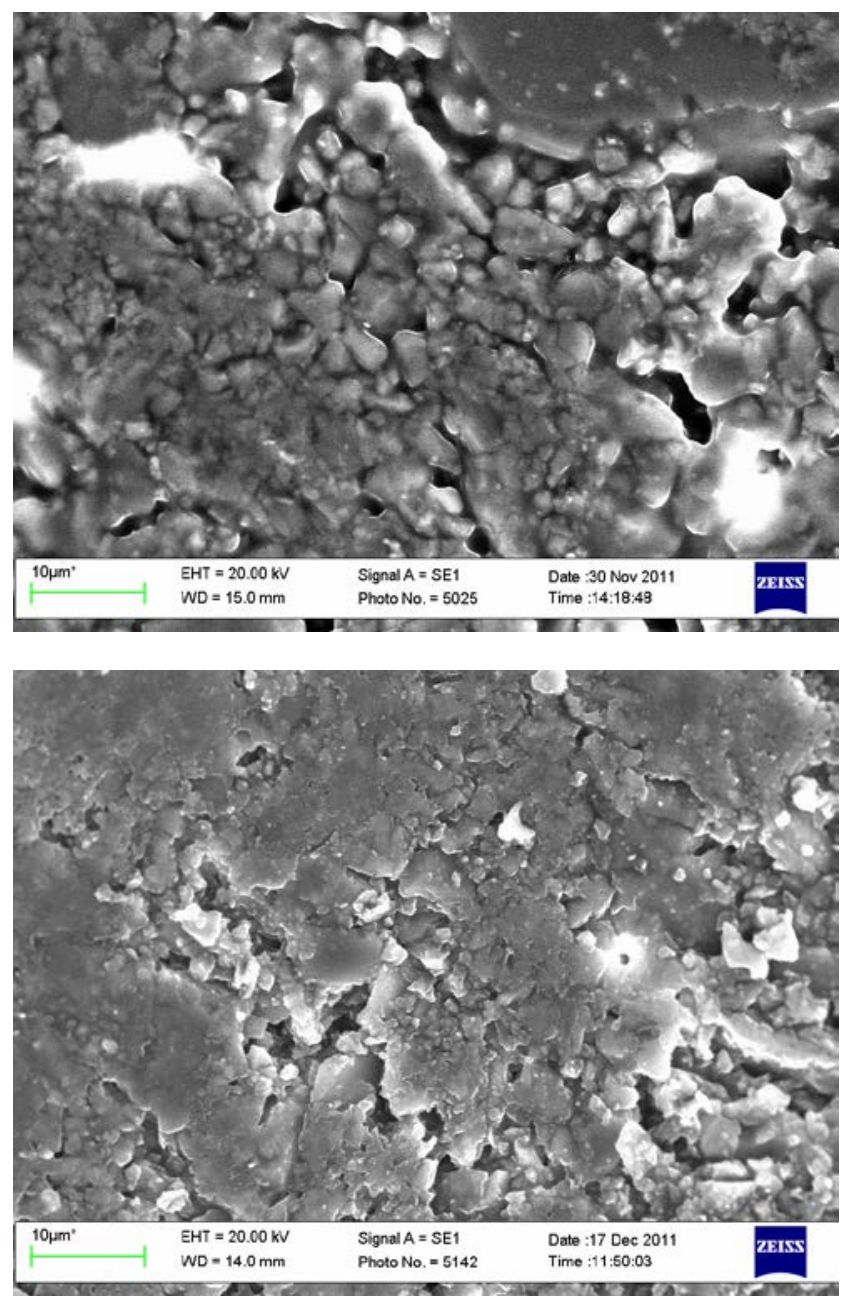

Fig. 3. SEM micrographs of archaeological ceramic sample coated with Paraloid B-82 (at top) and Silres BS 16 (at bottom) from monastery of "San Filippo di Fragalà" (Sicily, Italy)

Evidently, that the SEM images of coated with Paraloid B-82 and Silres BS 16 and un-coated ceramic samples are not similar suggesting that quality of polymer coatings is relevant. It is obvious that ceramic sample is evenly coated with Silres BS 16 . The polymer is distributed on the flat surface of ancient ceramic covering particles and spaces between agglomerated particles. Thus, from the SEM measurements we can predict that Silres BS 16 is more suitable chemical reagent for the conservation of ceramics.

The results of EDX analysis of ceramic samples are summarized in Table 1 . As seen, the main chemical elements determined in the ceramic samples are silicon, aluminium, carbon, oxygen and iron. The smaller amount of potassium and calcium was also found in the specimens. 
Interestingly, the amount of carbon is much higher in the coated ceramic samples in comparison with un-coated ones. These EDX results once more demonstrate that the surfaces of ceramic samples are saturated by polymeric compounds, which contain mostly carbon in their composition. Other determined elements are distributed evenly in the specimens.

Coated and un-coated ceramic samples were characterized by thermogravimetric (TG) measurements. The mass of samples used for the TG analysis was about $30 \mathrm{mg}$. The TG results are summarized in Figures 4, 5 and 6 and Table 2.

Table 1. EDX analysis data (mass \%) of un-coated and differently coated ceramic samples from monastery of "San Filippo di Fragalà" (Sicily, Italy). $n=10$

\begin{tabular}{|c|c|c|c|}
\hline \multirow{2}{*}{$\begin{array}{c}\text { Ele- } \\
\text { ments }\end{array}$} & \multicolumn{3}{|c|}{ Sample } \\
\cline { 2 - 4 } & un-coated & with Paraloid B-82 & with Silres BS 16 \\
\hline $\mathrm{C}$ & $20.16 \pm 0.12$ & $35.41 \pm 0.14$ & $26.74 \pm 0.12$ \\
\hline $\mathrm{O}$ & $40.19 \pm 0.21$ & $36.28 \pm 0.19$ & $36.33 \pm 0.20$ \\
\hline $\mathrm{Al}$ & $8.66 \pm 0.09$ & $7.89 \pm 0.08$ & $7.64 \pm 0.08$ \\
\hline $\mathrm{Si}$ & $19.13 \pm 0.12$ & $16.35 \pm 0.11$ & $17.52 \pm 0.13$ \\
\hline $\mathrm{K}$ & $2.96 \pm 0.07$ & $1.09 \pm 0.02$ & $3.49 \pm 0.06$ \\
\hline $\mathrm{Ca}$ & $1.56 \pm 0.02$ & $0.74 \pm 0.01$ & $1.76 \pm 0.12$ \\
\hline $\mathrm{Fe}$ & $4.99 \pm 0.12$ & $1.56 \pm 0.12$ & $4.51 \pm 0.02$ \\
\hline $\mathrm{X}^{*}$ & $2.35 \pm 0.04$ & $0.68 \pm 0.05$ & $2.01 \pm 0.03$ \\
\hline
\end{tabular}

* Others: Na, Mg, Ti, Cl.

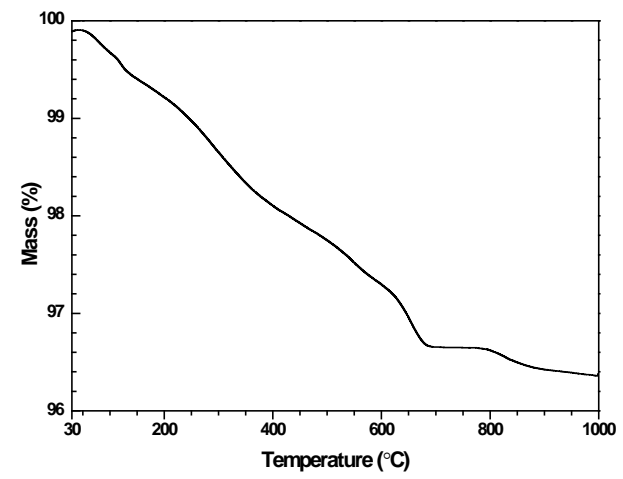

Fig. 4. TG curve of un-coated archaeological ceramic sample from monastery of "San Filippo di Fragalà" (Sicily, Italy)

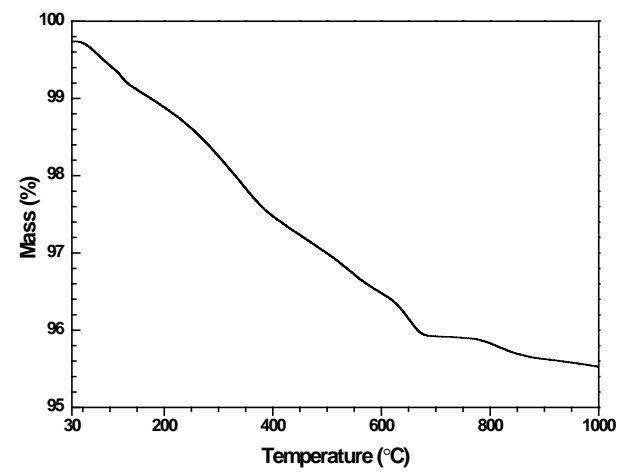

Fig. 5. TG curve of coated with Paraloid B-82 archaeological ceramic sample from monastery of "San Filippo di Fragalà” (Sicily, Italy)
The observed negligible initial mass loss from $0.39 \%$ up $0.56 \%$ for the ceramic sample in the temperature range of $30^{\circ} \mathrm{C}-150^{\circ} \mathrm{C}$ is associated with evaporation of moisture and water of crystallization [25, 26]. The second and the main mass loss observed between $150^{\circ} \mathrm{C}$ and $500^{\circ} \mathrm{C}$ is characteristic for pyrolysis of organic constituents and initial decomposition of metal salts. Interestingly, the larger mass loss in this temperature region was observed for coated with polymeric films ceramic samples. Thus, the TG results prove once again that ceramic samples are successfully coated with polymers. The last mass loss observed in the temperature range of $500{ }^{\circ} \mathrm{C}-800^{\circ} \mathrm{C}$ is due to decomposition of carbonates [18, 23].

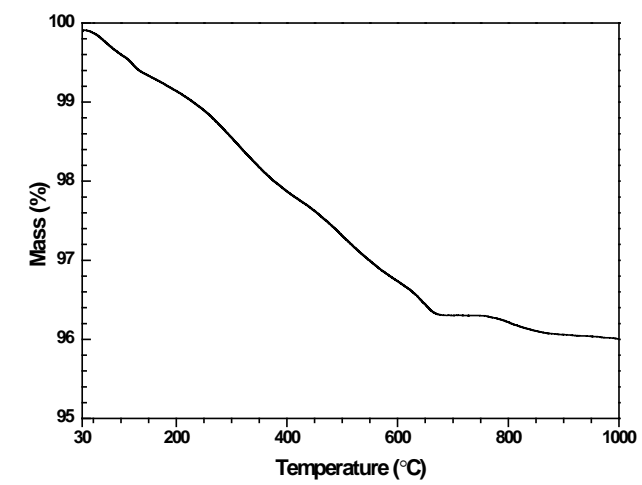

Fig. 6. TG curve of coated with Silres BS 16 archaeological ceramic sample from monastery of "San Filippo di Fragalà” (Sicily, Italy)

Table 2. TG analysis data of un-coated and differently coated ceramic samples from monastery of "San Filippo di Fragalà” (Sicily, Italy)

\begin{tabular}{|c|c|c|c|c|}
\hline \multirow{2}{*}{ Sample } & \multicolumn{4}{|c|}{ Mass loss, \% } \\
\cline { 2 - 5 } & $\begin{array}{c}30-150 \\
{ }^{\circ} \mathrm{C}\end{array}$ & $\begin{array}{c}150-500 \\
{ }^{\circ} \mathrm{C}\end{array}$ & $\begin{array}{c}500-800 \\
{ }^{\circ} \mathrm{C}\end{array}$ & $\begin{array}{c}\text { at } \\
995^{\circ} \mathrm{C}\end{array}$ \\
\hline Un-coated & 0.42 & 1.69 & 1.15 & 3.49 \\
\hline $\begin{array}{c}\text { With Paraloid } \\
\text { B-82 }\end{array}$ & 0.56 & 2.16 & 1.22 & 4.21 \\
\hline $\begin{array}{c}\text { With Silres } \\
\text { BS 16 }\end{array}$ & 0.52 & 2.05 & 1.14 & 3.88 \\
\hline
\end{tabular}

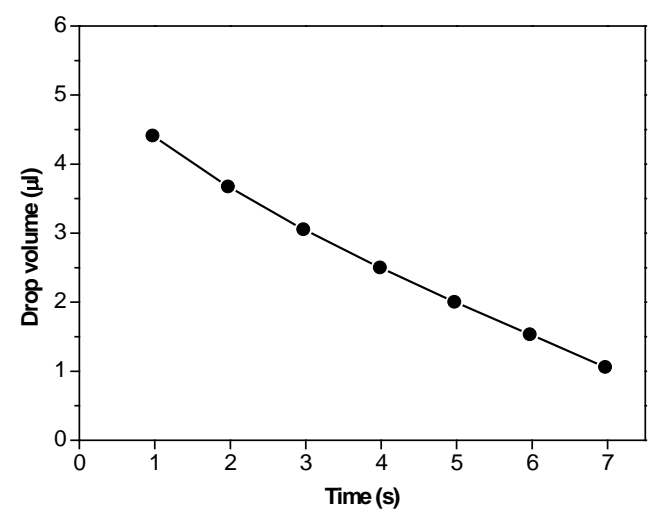

Fig. 7. The hydrophilic properties of surfaces of archaeological ceramic sample coated with Paraloid B-82 
The contact angle measurements were performed for all investigated ceramic samples. It was observed that volume of water drop on the surface of the un-coated sample decreased from $4 \mu \mathrm{l}$ to $1 \mu \mathrm{l}$ during 0.6 second, confirming low hydrophobicity of ceramics. The dependence of water drop volume on time for the ceramics coated with Paraloid B-82 is presented in Figure 7.

Evidently, the coating obtained with Paraloid B-82 was hydrophilic. It was determined that volume of water drop on the surface of coated sample with Paraloid B-82 decreased dramatically during few seconds.

The dependence of contact angle on time for the ceramics coated with Silres BS 16 is presented in Figure 8. As seen, the surface of sample coated with Silres BS 16 is hydrophobic [27, 28].

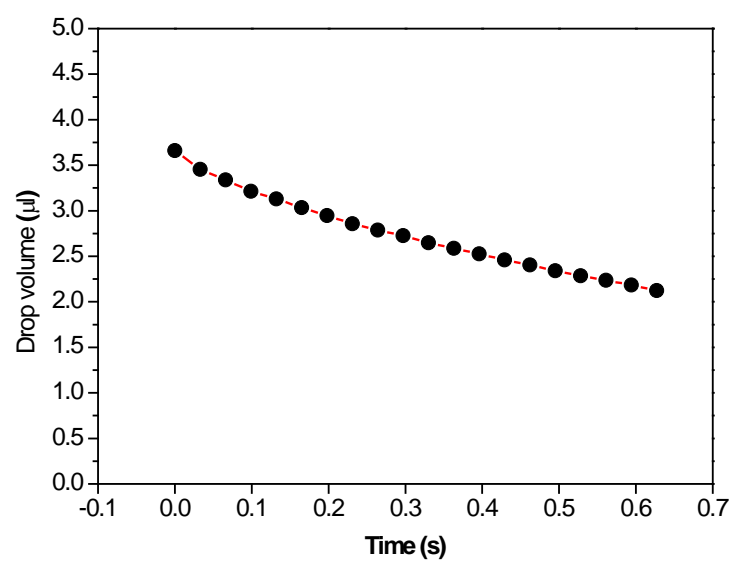

Fig. 8. The changes of contact angle on the surfaces of archaeological ceramic sample coated with Silres BS 16

\section{CONCLUSIONS}

New polymeric material Silres BS 16 (55 \% aqueous solution of potassium methylsiliconate) was suggested for the formation of protective coatings on historical outdoor ceramics from monastery of "San Filippo di Fragalà" (Sicily, Italy). For the comparison, the material Paraloid $\mathrm{B}-82$, which is already known in the conservation practice, was also used for the formation of protective coatings on historical ceramics. Polymeric films were investigated by the methods of SEM, EDX, TG and the measurement of contact angle. The TG and EDX results proved clearly that ceramic samples were successfully coated with polymers. SEM analysis showed that Silres BS 16 can be successfully used for the preparation of effective polymeric coating on ancient ceramics surface. Moreover, the measurements of contact angle showed that covering the ceramics by Silres BS 16 had the better protection from moisture in comparison with Paraloid B-82. Thus, Silres BS 16 is suitable for the conservation of ceramic samples containing ionic carbonates. Finally, new low cost and environmentally benign technological procedure for the conservation of outdoor ancient ceramics has been developed.

\section{Acknowledgments}

The study was funded from the European Community's social foundation under Grant Agreement
No. VP1-3.1-ŠMM-08-K-01-004/KS-120000-1756” and COST Action MP1202.

\section{REFERENCES}

1. Fairbrass, S. Sticky Problems for Conservators of Worksof-art on Paper International Journal of Adhesion and Adhesives 15 1995: pp. 115-120. http://dx.doi.org/10.1016/0143-7496(95)98747-A

2. Kiuberis, J., Tautkus, S., Kazlauskas, R., Pakutinskiene, I. Kareiva, A. Protective Coating for Paper: New Development and Analytical Characterization Journal of Cultural Heritage 6 2005: pp. 245-251.

3. Senvaitiene, J., Pakutinskiene, I., Beganskiene, A., Tautkus, S., Kazlauskas, R., Kareiva, A. Destructive Effects of Paper Conservation Procedure on the Writing Iron Gall Ink - Evidence from Transmetalation Reaction Polish Journal of Chemistry 79 2005: pp. 1575-1583.

4. Christensen, M., Frosch, M., Jensen, P., Schnell, U., Shashoua, Y., Nielsen, O. F. Waterlogged Archaeological Wood - Chemical Changes by Conservation and Degradation Journal of Raman Spectroscopy 37 2006: pp. $1171-1178$.

5. Shashoua, Y., $\quad$ Berthelsen, M. B. L. D., Nielsen, O. F. Raman and ATR-FTIR Spectroscopies Applied to the Conservation of Archaeological Baltic Amber Journal of Raman Spectroscopy 37 2006: pp. 1221-1227.

6. Pakutinskiene, I., Kiuberis, J., Bezdicka, P., Senvaitiene, J., Kareiva, A. Analytical Characterization of Baltic Amber by FTIR, XRD and SEM The Canadian Journal of Analytical Sciences and Spectroscopy $52 \quad$ 2007: pp. 297-304.

7. Daehne, A., Herm, C. Calcium Hydroxide Nanosols for the Concolidation of Porous Building Materials - Results from EU-STONECORE Heritage Science 1 2013: pp. 11-19.

8. Kiele, E., Lukseniene, J., Griguceviciene, A., Selskis, A., Senvaitiene, J., Ramanauskas, R., Raudonis, R., Kareiva, A. Methyl-modified Hybrid Organic-inorganic Coatings for the Conservation of Copper Journal of Cultural Heritage 2014.

http://dx.doi.org/10.1016/j.culher.2013.06.002.

9. Kareiva, A., Kiuberis, J., Merkevicius, A. Analytical Characterization of Baltic Amber and Pottery Archaeologia Lituana 12 2011: pp. 25-35.

10. Horie, V. Materials for Conservation. Elsevier Ltd., Oxford, 2010.

11. Sease, C. A Conservation Manual for the Field Archaeologist. Regents of the University of California, Los Angeles, 1994.

12. Vaz, M. F., Pires, J., Carvalho, A. P. Effect of the Impregnation Treatment with Paraloid B-72 on the Properties of Old Portuguese Ceramic Tiles Journal of Cultural Heritage 9 2008: pp. 269-276.

13. Petrenas, T., Zalga, A., Beganskiene, A., Kareiva, A. Investigation of Cation Migration from Non-conservated and Conservated Ceramic Surfaces Proceedings of 2nd Int. Conf. „Corrosion and Material Protection“ Ed. SVUOM Ltd., Prague, 2010: pp. 1-6.

14. Prudencio, M. I., Stanojev Pereira, M. A., Marques, J. G., Dias, M. I., Esteves, L., Burbidge, C. I., Trindade, M. J., Albuquerque, M. B. Neutron Tomography for the Assessment of Consolidant Impregnation Efficiency in 
Portuguese Glazed Tiles (16th and 18th Centuries) Journal of Archaeological Science 39 2012: pp. 964-969.

http://dx.doi.org/10.1016/j.jas.2011.11.010

15. Bescher, E. P., Pique, F., Stulik, F., Mackenzie, J. D. Long-Term Protection of the Last Judgment Mosaic in Prague Journal of Sol-gel Science and Technology 19 2000: pp. 215-218.

16. Dal Bianco, B., Bertoncello, R. Sol-gel Silica Coatings for the Protection of Cultural Heritage Glass Nuclear Instruments and Methods in Physics Research B 266 2008: pp. $2358-2362$.

http://dx.doi.org/10.1016/j.nimb.2008.03.014

17. Biscontin, G., Birelli, M. P., Zendri, E. Characterization of Binders Employed in the Manufacture of Venetian Historical Mortars Journal of Cultural Heritage 3 2002: pp. 31-37.

18. Iordanidis, A., Garcia-Guinea, J., $\quad$ KaramitrouMentessidi, G. Analytical Study of Ancient Pottery from the Archeological Site of Aiani, Northern Greece Materials Characterization 60 2009: pp. 292-302. http://dx.doi.org/10.1016/j.matchar.2008.08.001

19. Bani-Hani, M., $\quad$ Abd-Allah, R., $\quad$ El-Khouri, L. Archeaometallurgical Finds from Barsinia, Northern Jordan: Microstructural Characterization and Conservation Treatment Journal of Cultural Heritage 13 2012: pp. 314-325.

20. Beganskiene, A., Kiuberis, J., Raudonis, R., Kareiva, A. A Sol-gel Processing Route for the Conservation of Archaelogical Pottery Proceedings of 1st Int. Conf. „Corrosion and Material Protection“ Prague, 2007: pp. $1-7$.

21. Abd-Allah, R., Al-Muheisen, Z., Al-Howadi, S. Cleaning Strategies of Pottery Objects Excavated from Khirbet EdhDharih and Hayyan Al-Mushref, Jordan: Four Case Studies
Mediterranean Archaeology and Archaeometry

10 2010: pp. $97-110$

22. Abd-Allah, R. Chemical Cleaning of Soiled Deposits and Encrustations on Archaeological Glass: A Diagnostic and Practical Study Journal of Cultural Heritage 14 2013: pp. $97-108$.

23. Cardiano, P., Ioppolo, S., De Stefano, C., Pettignano, S., Sergi, S., Piraino, P. Study and Characterization of the Ancient Bricks of Monastery of „San Filippo di Fragala“ in Frazzano (Sicily) Analytical Chimica Acta 519 2004: pp. 103-111.

http://dx.doi.org/10.1016/j.aca.2004.05.042

24. Petrenas, T., Kiuberis, J., Opuchovic, O., Tautkus, S., Kareiva, A. A Closer Look at the Ancient Bricks of Historical Monuments: Essential Step for the Conservation of Pottery Chemija 23 2012: pp. 194-202.

25. Moropoulou, A., Bakolas, A., Bisbikou, K. Thermal Analysis as a Method of Characterizing Ancient Ceramic Technologies Thermochimica Acta 257 1995: pp. $743-753$.

26. Palanivel, R., Kumar, U. R. The Mineralogical and Fabric Analysis of Ancient Pottery Artifacts Ceramica 57 2011: pp. 56-62.

27. Jung, Y. C., Bhushan, B. Contact Angle, Adhesion and Friction Properties of Micro- and Nanopatterned Polymers for Superhydrophobicity Nanotechnology 17 2006: pp. $4970-4980$.

28. Sadat-Shojai, M., Ershad-Langroudi, A. Polymeric Coatings for Protection of Historic Monuments: Opportunities and Challenges Journal of Applied Polymer Science 112 2009: pp. 2535-2551. http://dx.doi.org/10.1002/app.29801 